\title{
Teaching Online in an Ethic of Hospitality: Lessons from a Pandemic
}

\author{
Rebeca Heringer $^{1}$ id
}

Accepted: 21 June 2021 / Published online: 3 July 2021

(C) The Author(s), under exclusive licence to Springer Nature B.V. 2021

\begin{abstract}
With the outbreak of COVID-19 pandemic in 2020, teaching online became a norm for universities in Canada. Besides the challenges of teaching topics that may be impossible to be taught online, a major issue that the mandatory physical distancing brought is the relationality between teachers and students. In order to investigate how educators were making sense of such changes, semi-structured interviews were conducted with 12 education professors across Canada. In light of Derrida's and Ruitenberg's ethic of hospitality, this paper explores how the abrupt shift to online education unveiled the nature and challenges of hospitable education, especially in the online context. The implications of online instruction to professors' relationality, however, are also instrumental in illuminating the complexities and ambiguities of a teacher's responsibility even in what could be considered the "normal circumstances" of face-to-face instruction.
\end{abstract}

Keywords Ethic of hospitality $\cdot$ Social presence $\cdot$ Online education $\cdot$ Higher education

\section{Introduction}

The year of 2020 was marked by the outbreak of COVID-19 around the world. In Canada, while the closure of public schools lasted from March to September, university campuses remained closed in the Fall term, with courses having to be delivered online. As online education is not a new phenomenon per se, many researchers have already explored how teachers adapt their practices (Badia et al. 2017; Moreira 2016) and how teachers perceive online courses (Comas-Quinn 2011; Cook 2018; Gonzalez 2009; Murphy, RodríguezManzanares, \& Barbour, 2011). However, the relationship between teachers and students in the online context, although relevant (Woods \& Baker 2004), is an area which has not been well explored from the teacher perspective, especially in higher education (Hagenauer \& Volet 2014).

I confirm that this work is original and has not been published elsewhere, nor is it currently under consideration for publication elsewhere.

Rebeca Heringer

heringer@myumanitoba.ca

1 University of Manitoba, 26-1048 Grant Avenue, Winnipeg, MB R3M 2A3, Canada 
Indeed, the abrupt shift to online teaching raised many questions as to how to adapt practices to this new environment. But while certain topics are indeed challenging (if not impossible) to be taught from a distance, a major concern that arouse from this context is around relationality. As a participant from this study observed, "You can be socially distant, and you can wear a mask, you can protect yourself and students can protect themselves but there's no messaging around how we can foster interactions in spite of these challenges that we are facing" (Fabien). When ethics is understood as relation rather than a component of it, as Levinas articulates, how can education (ethically) take place in an online environment? The purpose of this paper is to explore the ways in which the abrupt shift to online education unveiled the nature and challenges of an ethic of hospitality. Although stemming from the online context, the implications of online instruction to professors' relationality are also instrumental in illuminating the complexities and ambiguities of a teacher's responsibility even in what could be considered the "normal circumstances" of face-to-face instruction.

\section{Relationality in Online Education}

Many of the benefits and challenges of online education have been widely registered in the literature (e.g., Afrouz \& Crisp 2021; Davis et al. 2019; Jones 2015; Reamer 2013). For instance, convenience, flexibility and inclusion of diverse learners are often noted as characteristics that have greatly contributed to the increase demand for online education in the recent years. On the other hand, course quality, disempowerment, privacy and isolation are some of the challenges of online education commonly noted by research worldwide (e.g., Afrouz \& Crisp 2021; Burke \& Larmar 2020; Davis et al. 2019; Reamer, 2013). For that reason, many studies emphasize that teacher social presence is essential to students' engagement, satisfaction and learning in the online context (e.g., Raza et al. 2020; Song et al. 2019; Sung \& Mayer 2012).

Social presence is a complex term, but it can be defined as "perceptual experience of being psychologically involved in the interaction with others in a mediated environment" (Song et al. 2019, p. 449). The term can thus be understood as an attenuated form of presence, a feeling of community that allows learners to feel connected on a human level. Social presence is then often interpreted instrumentally as a way to keep students engaged enough in the class to learn the material. As Biocca et al. (2003) argue, social presence does not require physical presence and thus is not binary as physical presence is. The sense of being together can exist through the mediation of interfaces, hence the importance given to immediacy in the literature. Amongst the innumerous possible definitions, immediacy can be understood as "the psychological distance between a communicator and the recipient of the communication" which is conveyed "through speech and associated verbal and nonverbal cues" (Tu \& McIsaac 2002, p. 134).

But while immediacy and social presence are common concepts in the related literature, they are mostly used either to address students' perceptions of their teachers or as strategies employed by teachers to foster student learning and engagement. There is a paucity of research, however, that investigates how such terms relate to and evidence the challenges and complexities of a teacher's relational responsibility in the online environment as an ethic of hospitality would require-a discussion that this paper seeks to bring forward. 


\section{Education as an Ethics of Hospitality}

For Levinas $(1972,1982,1995)$, the singularity of the face of the Other (Autrui, absolute other) indicates how despite its proximity, alterity is irreducible, beyond comprehension, and something I am infinitely responsible for. For Levinas, the attempt to know, understand, categorize the Other, means trying to reduce the infinity of the Other to what I can comprehend, possess, thus an act of violence to their uniqueness. Therefore, rather than trying to understand how the Other differs from me, it is my responsibility to uphold and respond to the Other's uniqueness as it appears and without expecting anything in return. Responsibility, for Levinas, is thus immediate, asymmetrical and unlimited.

Following Levinas' conceptualization of responsibility, Derrida dedicated great extent of his work to analyzing the question of hospitality. While Kant had touched on it in Perpetual Peace, in 1795, Derrida explores a conceptualization of hospitality that is not bound by territory but is rather unconditional, offered to the one we do not even know the name. Even though Derrida did not apply the metaphor specifically to the realm of education, its postulates have been greatly embraced by academics when conceptualizing hospitable education (e.g., Biesta \& Egéa-Kuehne 2001; Bryzzheva 2018; Hung 2013; Peters \& Biesta 2009; Ruitenberg 2016; Zembylas 2020). Although the characteristics of hospitality can be analyzed in different ways (cf. Ruitenberg 2009), the metaphor may be well summarized by pointing out that genuine hospitality is unpredictable, unconditional, and uncomfortable.

\section{Unpredictable}

Firstly, Derrida emphasizes that hospitality is truly evidenced not when it is offered after careful planning. Rather, hospitality is expressed when the host is caught by the surprise of the unexpected knock on the door. As Derrida (2007) explains, "there can be an event only when it's not expected, when one can no longer wait for it, when the coming of what happens interrupts the waiting" (p. 443). While one may wonder about and conceptualize the arrival of an Other, genuine hospitality-as an event-is unforeseeable, vertical. The arrival of the Other, with its absolute alterity, will then always be a complete surprise.

Applying the metaphor to the realm of education, Ruitenberg (2011) illustrates the idea with another metaphor: the empty chair carefully and thoughtfully placed in the classroom. The Other may or may not arrive, but if that moment comes, there will be room for them. In other words, the teacher-host must invest time in preparation for the student-guest who might arrive, but in a way that intentionally engages in the deconstruction of their own planning. As Ruitenberg (2016) puts it, the teacher should be constantly asking oneself: "Does what I am about to do leave a possibility for my assumptions about knowledge and teaching and learning to be upset by a new arrival? Does it close down a space for future questioning or questioners?" (p. 30).

\section{Unconditional}

In a similar vein, when conceptualizing ethics as relation Derrida concurred that the self is unconditionally responsible for the uniqueness of the Other, whoever that may be, for only then will one be able to respond to the complete unknown Other: "absolute hospitality requires that I open up my home and that I give not only to the foreigner...but to the absolute, unknown, anonymous other... without asking of them either reciprocity (entering a pact) or even their names" (Derrida 2000, p. 25). Receiving a beloved one at home may 
not be a big challenge, but "hospitality is not merely receiving that which we are able to receive" (Derrida 2007, p. 451).

Following this idea, Ruitenberg observes that the ethical challenge for educators does not lie on having a perfectly prepared class in response to who I think I already know or understand. As Derrida (2007) puts it, "I must not even be prepared to receive the person, for there to be genuine hospitality" (p. 451). If genuine hospitality requires not trying to mold or contain the Other into my own understanding, the challenge for educators is rather to respond to that "fundamentally ungraspable ... student ... in a way that lets her or him be in otherness, that does not seek to recognize or otherwise close the gap with this singular other" (Ruitenberg 2011, p. 32).

\section{Uncomfortable}

Given its unpredictable and unconditional nature, genuine hospitality is thus inevitably uncomfortable for the host. Moreover, in addition to not knowing when or who, the host is a "hostage" to the Other (to use Levinas' terminology) for not expecting anything in return or ever even knowing if hospitality has in fact taken place. In fact, the aporia of hospitality is evidenced in its own definition, for to say "welcome" to the Other is already to demarcate the threshold of one's property. Saying "make yourself at home" is to already tell the Other that that is not their home. Derrida (2007) therefore emphasizes that "the event, if there is one, consist in doing the impossible" (p. 449) because the impossibility of hospitality "continues to haunt the possibility... it may have taken place but it's still impossible" (p. 452). The im-possibility of responsibility (Fagan 2016) also stems from the fact that there is always another Other present (or the Third, as Levinas put it). Therefore, as Fagan (2016) summarizes,

within the demand for unconditional justice, absolute duty and so on, there is always already, immediately, the necessity and demand to submit to the demands of generalization, calculation and conditionality. It is this double imperative, from the limits of theory, which undoes the certainty of all of theoretical claims. (p. 97)

The im-possible nature of genuine hospitality thus shakes teachers' sense of security and comfort that would stem, for example, from feeling in control of the class and having students responding to the lesson as expected. However, Ruitenberg (2016) clearly explains that,

In an ethic of hospitality, the question is not whether the host feels comfortable in the presence of the guest. In fact, the openness to the other required in an ethic of hospitality means that the arrival of the other may destabilize the host's prior sense of self. (p. 30)

\section{The Present Study}

In the midst of the challenges of an unprecedented time, the purpose of this paper is to explore the ways in which the abrupt shift to online education unveiled the nature and challenges of an ethic of hospitality, especially in the online context. A purposive sampling was used to recruit 12 professors who teach at faculties of education in 4 different Canadian provinces (Ontario, Alberta, Saskatchewan, and New Brunswick) and who were teaching 
online as a direct consequence of COVID-19. Semi-structured interviews were conducted with participants through Zoom and a pseudonym was attributed to each professor at the time of transcription. Each interview lasted for about 30 to $50 \mathrm{~min}$. At the time of the interviews, professors had between 2 and 22 years of experience in their institutions. Participants had the opportunity to revise and edit their interview transcript if they wanted to. In order to protect professors' identities, I chose not to disclose their institutions or associate their quotes with provinces. This research was approved by the Ethics Review Board of the University of Manitoba. Although the small sampling may not allow this research's findings to be generalized to the whole country or other educational settings, this paper may serve to illuminate how the complex postulates of the theoretical construct of hospitality may inform teachers' conceptualization of relationality and responsibility regardless of the context. The collected data was thematically analyzed and reorganized with special attention to the complexities and ambiguities in enactment of a teacher-host's responsibility in the online environment, which I present and discuss in the next sections.

\section{The Unforeseen Silence that Speaks}

Certainly, the shift to online education as a consequence of COVID-19 pandemic was unforeseeable in itself. But as most participants had never taught online, this new format was an added unprecedented experience. The majority of participants expressed how their first strategy was to try to reproduce the in-person class. As Fabien said: "it's my desire to make it as similar to a face-to-face environment as possible". However, some professors realized that in trying to do that they were often being unsuccessful, the lack of responsivity being one of its evidences, "like pulling teeth" (Helen) from "a wall of silence" (Anthony). This unforeseen context created a perceived "strange muffled atmosphere" (Brianna), which required participants to be attentive to different types of communication during class so as to overcome the uncomfortable silence they were encountering. Examples of those were the chat box and non-verbal icon reactions (e.g., thumbs-up, claps, smile). As Brianna observed, "you don't realize how much you are tethered to the body signals of a group of people when you are teaching". Communication out of class was another noticeable component that was affected by this new modality. Most professors mentioned how before the pandemic they would always arrive in class earlier or leave later and have their office doors opened for students to come in. During the pandemic, however, professors felt the urge to be tuned to their emails and available seven days a week and in non-habitual times "because I never know when a student is going to write" (Deborah).

While having the doors of one's office open might be perceived as a gesture of unlimited welcoming, looking through the lens of an ethic of hospitality I argue that underneath such open-door policy is still the control of when and where the teacher-student encounter can take place. Then, when teaching online, professors felt that they were "trying to enact that same kind of responsiveness and openness in the digital realm" (Gabriella). But given that during the pandemic the only way that a student could reach out to professors was through email (or another online platform), unless professors turned off their internet/notifications they were bound to be contacted by students at any time. In other words, what might have been perceived as unconditional hospitality prior to the pandemic was still limited to the office hours or the physical presence of the teacher in the classroom before or after class. During the pandemic, what might have been perceived as unconditional hospitality could have been a reflex of the inevitability 
of being connected to the internet which, in turn, may have been conducive to their being in contact with students more often. In such context, professors could often assure students of their presence so they "feel that someone is really caring for them" (Ian). Furthermore, if prior to the pandemic professors could have taken longer to reply to a student's email, it seems that it was the present context that heightened their concern for students' well-being-an aspect that I return in the next section.

So, although the literature shows that social presence is a much greater concern in online classes, what is clearly common among participants is how their perceived urgency was linked to the stress and challenges caused by the pandemic, not necessarily the immanent responsibility to the invisible face that would speak at an unpredictable time. This may be noticed by the fact that some professors observed that the familiarity with the medium became a potential threat to their own practices as well. That is, how the physical absence of students, even if just for a brief moment, led them to "hide" themselves behind the screen. As Fabien said, "I need a constantly reminder that I'm going through, as I'm preparing for my courses, because it is quite easy to distance yourself from this because of the technology".

Jones (2015) observes that the quality of interaction is affected by the different education formats, spontaneity being part of the equation. Yen and Tu (2011) also note that the absence of non-verbal communication and social cues can pose challenges and lead to frustration and miscommunication between teachers and learners. As Davis et al.'s (2019) research also alluded to, some professors in the present study feel that the lack of connection makes the class "a little bit less emotional" (Gabriella) and impinges on students' sense of accountability, often leading them to be silent, disruptive and even disrespectful-situations they believe could have been avoided in a face-to-face class with different "management strategies" (Gabriella). As Helen illustrates:

... it's interesting because a couple of times they all had their screens on and I jumped into the meeting and a couple of them shut their screens off... all I was doing was checking-in and they were shutting their screens off and I was like "what just happened?" I mean, I didn't say that to them but when I was jumping between the 4 groups I thought that was really weird. Maybe that's normal. I don't know, I don't know what's normal teaching online. But I thought it was a little weird, I was offended, put that way. I was offended.

Having been removed from the comfort of the classroom and forced to enter an unknown environment was felt by most professors as a source of worry and tension. However, it also serves as a reminder that "in an ethic of hospitality, [teachers] can offer hospitality to newcomers only in the spaces in which they themselves are guests" (Ruitenberg 2016, p. 25). Hospitality is not an exchange, but an unconditional, ongoing and unforeseen gift that stems from a unique encounter. Approaching students with pre-conceptualized gifts will not only fail to respond to students' uniqueness but also potentially become a burden to teachers who may feel unequipped or even offended by a perceived lack of acceptance of the gift. Recognizing her own tendency to expect reciprocity from students, Ruitenberg (2016) observes:

If students leave classes early, or do not attend all classes, I may interpret this as a personal affront... But when I pause and ask myself who or what is being affronted, I discover a rather inhospitable and controlling teacher. (p. 81)

Conversely, hospitable education is about responding to the uniqueness of the unknown Other in the unique context created by our unique encounter in time and space, without 
trying to reproduce what is known to me-i.e., responding based on what I have experienced (and mastered) in the past.

\section{A Hostage to the Other Behind the Screen}

At the same time that some professors saw the opportunity to be connected with people from all over the world as something positive, all participants commented how challenging it had been for them to meaningfully connect with students. An evidence of the challenge was mentioned by John, who noted that a teacher may be able to recognize students' faces, but not names, after years. Thus, not able to "put a name to some of the faces", a common remark among professors was "I don't feel I know my students at all", as Helen said. Mary's question was also at the heart of this study: "I had half of them with a blank screen. And ethically how do you connect with a blank screen?".

Surely the psychological effect of students' physical presence in the face-to-face context may have outweighed any lack of social presence on their part (cf. Biocca et al. 2003), which maintained professors' engagement and responsivity. Not surprisingly, unable to count on students' physical presence anymore, most professors emphasized how challenging it had been for them to be responsive to students because "they feel much farther away from me relationally", as if there were "a big gap there" (Anthony). As the literature also alludes to (Sung \& Mayer 2012), professors in this study were feeling "disengaged" with their students and that "it's harder to care about people you don't meet" (Edmund).

Notwithstanding, a common observation among participants was that they were now even more sensitive to students' comfort, valuing their well-being more than the content to be taught or assignment deadlines, and more about "learning how they are doing as people, on a more personal level" (Ian). But the sensitivity to students' well-being also led professors to face the tension between their willingness to be supportive and the increase of their workload. In the interviews, professors stated how teaching had blended in their day, where the boundaries between work and home were not so clear anymore and where "time has lost its rhythm" (Deborah). Some participants were feeling how the amount of feedback and preparation was even causing them "physical strain" (Gabriella).

As Jones (2015) observes, social presence in online education requires creativity and extensive investment throughout the week. While email communications were already present before the pandemic, this being the only way in which students could reach out to professors outside of the classroom time raises the question of when and how often teachers should respond to students. Burke and Larmar (2020) and Jones (2015) note that it is necessary that teachers of online courses establish clear boundaries with students from the outset so that interactions can take place in a timely and supportive manner while respecting the realities of instructors' own limitations. So, despite being potentially more sensitive to students' needs, some professors in the present study also commented that they had also been seeking to respect their own well-being and "exercise boundaries to figure out worklife balance" (Brianna). Gabriella, for example, mentioned that she opted for asynchronous classes for her own well-being and being able to care for her young child. Edmund, in turn, felt that his responsibility to himself meant recognizing his limitations and that "there is no way I can offer the same course I did last year or the year before".

While there is an increased expectation of teacher presence in online education as research shows its positive influence on student engagement and learning, Ruitenberg (2016) explains that hospitality is not necessarily a student-centered pedagogy, because "a 
strong student-centeredness can become a way of abandoning one's responsibility as an educator" (p. 91). Expanding on Ruitenberg's original argument, I argue that hospitality is not necessarily student-centered because the host's wellness does matter. That is, because hospitality requires a guest and a host to take place, hospitality must be sustainable lest it eliminate the host. The threshold of one's property is both what makes the host a host and what allows the host to (un)welcome the guest. Some professors felt that they were more sensitive to students' well-being as well as their own, but they were still trying to understand how to do so without letting it impinge on their responsibility. It might be argued, though, that instructors were not necessarily more successful in attending to everyone's well-being, but that the pandemic context pandemic context made those efforts more pressing. Given that hospitality is not bound by one's professional duties nor contingent upon a pandemic, the question that arises to be further explored (Author, forthcoming) thus is: how can hospitality be infinitely asymmetrical and unconditional without neglecting the host's well-being?

This study also complexified the notion of social presence and raised the question of what quality of presence demands responsibility. As it seems, teachers' perceived responsibility before the pandemic may have over-relied on the physical presence of the student. However, just like it is possible for the teacher to be socially present while physically absent, student presence escapes the presence of the face-the face is in fact just the trace of that which is infinite, as Derrida (1978) argues. When Levinas speaks of the face, he does not mean necessarily a literal face. The face is an expression of the proximity and infinitude of the Other, what cannot be reduced to perception (Fagan 2016). The self's responsibility "begins" not by seeing the face but by hearing its voice, being exposed to the disquieting impact of alterity which "places the ideas of my autonomy and identify in question" (Fagan 2016, p. 53). As Derrida (2007) observed, "because I'm responsible for the other and it's for the other that I decide; it is the other who decides in me, without in any way exonerating me from 'my' responsibility" (p. 455).

Different from Burke and Larmar (2020) who, based on Nodding's ethics of care, claim that "an online pedagogy of care begins with relationships" (p. 6, italics in the original), hospitable education is not focused on the relationship between self and Other but on the Other as Other. While it does begin with a social encounter, hospitality (and hospitable education) entails an immediate and responsible response to alterity-although that is not a synonym of being Other-centered. While the pandemic context exacerbated the unpredictability of people's lives and heightened professors' sensibility to such unforeseen events (as every event is [Derrida 2007]), hospitality is not limited to compassion or empathy. Hospitable education goes beyond an ethics of care because it is not about morals, virtues or politics, but about immediate and unconditional responsibility, something that is not focused on the relation itself but the uniqueness of the Other. In other words, a teacher may not care about the student but that does not eliminate one's responsibility towards them. Responsibility, Levinas shows, is immediate. The face of the Other is always there, naked and vulnerable, thus making the self infinitely responsible for them. The way in which one chooses to respond, however, may or may not be responsible-whether it is out of care or not. Care or empathy in themselves are not enough because those can be ultimately self-centered relations (Todd 2003). Therefore, a question that arises from these findings is whether professors' pressing and arguably tactful responses to students would still be haunting them were they not in the context of a pandemic. Finally, if the increased demand for online education in the twenty-first century appeared to threaten face-to-face classes, the interviews and outcomes of COVID-19 demonstrated how the teacher-host is indeed irreplaceable. Physical presence may not be necessary, but personhood remains essential 
not only to student engagement and well-being (Burke \& Larmar 2020; Song et al. 2019), but to the possibility of hospitality.

\section{Vulnerability and Self-Disclosure}

Research shows that teacher self-disclosure is a major component of social presence and positively associated with student satisfaction and consequent learning outcomes (Raza et al. 2020; Song et al. 2019). Self-disclosure can be understood as a conscious and intentional process of revealing personal information to others which, Song et al. (2019) observe, tend to be carefully selected. However, the abrupt shift to online education meant that professors who were not used to teaching online when the pandemic hit had to suddenly face the "vulnerable" and "intimidating" challenge of being exposed to students on the camera in their own homes.

Indeed, privacy is a major ethical issue that has been associated with online education (Reamer 2013). In the present study, only one professor said that they make the use of camera mandatory-albeit not penalizing students who claim to be having issues with the technology. In most cases, it seems that it was professors' own recognition of how uncomfortable being on the camera in one's home can be, "like you are crossing into your private life" (Deborah), that have led them not to demand that from students-although this is something they encourage and thank.

The unconditional nature of hospitality suggests that "the guest, the invited hostage, becomes the one who invites the one who invites, the master of the host" (Derrida 2000, p. 125). Because teachers had no option in synchronous classes but to have their cameras on (while not being able to demand the same from students), it seems as though they were experiencing not only a feeling of discomfort but also powerlessness to some extent. This context, however, pointed to relevant aspects regarding teacher control and identity, which are at the center of hospitality. As this participant notes:

We're opening ourselves up in healthy and not healthy ways that we've never done before. And I think it gets at relationship, but I think it also raises questions about identity both for our students but also for us as professors. (John)

Indeed, hospitable education is not about exercising mastery of a medium or being comfortable with the classroom (whether virtual of not) as if we owned it. In fact, as Derrida argued, genuine hospitality will necessarily be uncomfortable for the host. Because responding to the Other in their otherness means necessarily escaping the confinements of the self, educators in the pursuit of hospitable education should be in a constant process of self-reflexivity and questioning the ways in which their comfort with the classroom and practices may be a result of their "irresponsibility".

Moreover, the abrupt shift to the online format meant that professors had to learn how to navigate platforms and use programs they were not used to, demanding extra effort and enhancing their sense of insecurity because "I make mistakes, I hit the wrong buttons" (John). Having to learn about new apps and technologies was thus perceived as "time-consuming", "demoralizing", "tough", something which "introduces some layer that bumps up against our relationship and responsibility" (John). While it is undeniable that learning new technologies can be time-consuming, their perceived insecurity may also be directly associated with a common idea that teachers ought to be in control of everything that happens in the class. Conversely, some professors had no choice but to accept students' help with 
technology during class-and some even received feedback after class to congratulate them on their success with it.

Implications of these findings question the extent to which educators may over-rely on certain mediums as being the best approach to teaching a certain topic. An ethic of hospitality demands that the teacher-host be ready to adapt to unforeseen circumstances and respond to the uniqueness of each person in each unique context they are in-a complex and multifaceted challenge that the pandemic evidenced.

\section{Longing for Feedback}

In this study, professors' pursuit of immediacy to foster students' learning experience was not followed by the rewards they were used to getting. Students' faces and body language used to give professors a major sense of security in the face-to-face context, both as a source of feedback to their practices (e.g., knowing whether students were understanding or enjoying) and to sustain their perceived "sense of control" (Louise) (e.g., knowing who is in the classroom and doing what). As Charles said, "If I see you smiling and looking happy, that's good". But teaching in this new context "brings out insecurities" (Louise); "I'm talking away about whatever and I have zero idea whether they are listening, if what I'm saying makes any sense, whether what I'm saying is any interesting... it's like I'm talking to a wall, literally" (Charles). Therefore, while seeking to respect their privacy, being able to see students' faces and seeing that "they are at least there" (Ian) served to greatly alleviate professors' anxieties and insecurities. However, professors emphasize that at the end of the day, it is students' choice whether they want to have their camera on or not, and that their comfort should come first.

Without the feedback they were used to having, though, professors often commented how challenging and demotivating the experience had been for them, frequently speaking in term of "loss", "grievance", "loneliness", "void", "nothingness" and "emptiness", which makes them feel that the class is "not as alive, it's not as engaging" (Anthony). The common small talk that used to follow professors in the hallway was contrasted with the abrupt "End meeting for all" button that ends the online class and whatever energy was going on between teachers-students. As Anthony said, not "being fed the energy from the students" and "the rewards of feeling like a lift from being in front of the class, which I usually get" is "definitely not as fun".

However, it is possible to observe that seeing students' face also seemed to trouble professors. As Louise said, "there's an emptiness of always talking to a screen, even if there is a person". Deborah shared the same feeling:

I feel excited when I see people in there, but there is also a loneliness... I was always sad after I left the meetings because we were not together, right? So it is with mixed feelings. I think one of the biggest challenges in trying to convert everything online is that there is this grieving process that, you know, in one of the classes I have 77 students, I'm not going to know them in the way that I am used to knowing students in the face-to-face environment. (Deborah)

As professors alluded, this feeling of grievance may be due to the pandemic context we were living in, when physical distancing was not an option. However, Derrida (1978) observed that the face is not just a surface, the face "is also that which sees... which exchanges its glace" (p. 98). The face, as an expression of infinity, speaks; "le visage me demande et m'ordonne" 
[the face asks me and orders me] (Levinas 1982, p. 94), which is why Derrida (1978) argues that "violence, then, would be the solitude of a mute glace, of a face without speech" (p. 99). Being able to see students but not necessarily have their social presence to a desired degree (as they thought they had before) was perceived as a tombstone, the remembrance of was not there, what could not be present. In his semiotic works, Derrida states that every sign (as the words) points to what is absent, it grieves. Every representation is a misrepresentation because what is unique cannot be re-presented, it cannot be contained in a sign-the face being but a trace of infinity. Thus, both seeing and not seeing students' faces behind the screen functioned as an illustration of that which cannot be contained.

The subjective quality of social presence, however, is certainly something complex to measured (Biocca et al. 2003) and corroborates the idea that hospitality is not something that can be premeditated or limited to one's professional duties because it is contingent upon a unique interaction in a unique context. While most studies related to online education have focused on the ways in which teacher immediacy positively influences student satisfaction and learning, an ethic of hospitality focuses on the host's responsibility when receiving the Other, not on student achievement or learning outcomes. In other words, hospitable education is not a means towards an end-it entails a disposition that goes beyond what one will get as a result. Hospitable education is an immediate and infinite responsibility that is not bound by professional duties and not just a means to foster student learning and engagement.

While the extent to which physical presence is (not) a synonym of social presence seemed to be unquestioned by professors, the interviews revealed how students' presence in the online classes is not a synonym to social presence. Notwithstanding, in the online context professors had to be contented with the unexpected ways in which students made their presence known and had to respond to their personhood "as it turned up" (to use Derrida's [2000] expression). The metaphysics of presence that seems to have guided professors' practices before the pandemic was put in question with the physical absence of students and greatly distressed participants who, even when seeing them, were not empowered to comprehend them as they used to. The undesirability of totalization and impossibility of grasping one's uniqueness was evidenced by the unreachable Other behind the screen.

This study thus points to the asymmetrical and unconditional nature of hospitable education. The absence of students' faces, which professors relied so much on to guide their classes and their own sense of accomplishment, was heavily felt by participants who expressed feelings of loss, grievance and emptiness. Curiously, Derrida (2007) notes that "there is a certain affinity between hospitality and mourning" (p. 453). Not being able to rely on the power and familiarity with the medium they used to have served to demonstrate that in genuine hospitality we never know if we are being successful, if the Other has accepted the gift, if hospitality has taken place. Although before the pandemic professors may have assumed that students felt welcome based on their body language, the inevitable grievance of hospitality is its impossibility (Fagan 2016) and the fact that it is only the guest who may finally claim "I am welcome".

\section{The Healthy Discomfort of Disempowered Teaching}

One trait of hospitable education is the discomfort experienced by the host who is a hostage to the alterity of the Other. This study illustrated how responding to unique encounters may often lead to perceived feelings of powerlessness. Participants expressed uneasiness given the uncertainties of teaching online, especially as it relates 
to achieving their goals without the strengths they believe they had prior to the pandemic, such as supplying materials or being able to engage students physically. Mary, for example, commented how she had carefully and thoroughly planned an activity where students would do movements in front of the camera, but that she had to change it in response to students' reaction:

I was so excited to get that started but they just stared at me and I was the moving one and they were sitting at their computer because I realized they hadn't associated movement with computer yet. They thought of computer as a sit-down modality. And I was introducing movement, that didn't register. So in that moment of responsibility I sat down and I calmed down and I said, ok, how are you? (Mary)

As it seems, in the first moment professors' judgement of their responsibility was tied to and based on their face-to-face encounters. Such conceptualization is not only unproductive (given the impossibility of reproducing what cannot be present) but also posed a burden on professors who felt unequipped to fulfil their responsibilities. Some professors, however, observed how the unprecedented context they were teaching in was nonetheless "forcing some healthy changes too" (Edmund). Although participants emphasized that their pedagogical philosophies had not changed, most professors commented how much time they were spending rethinking their practices to be able to sustain their values while trying to achieve their goals and to "connect with the learners in a more relational level" (John).

Some professors commented being aware, even before the pandemic, that each class is a unique response to the group of learners in that term. As Edmund puts it, "I adapt very much depending on how the class is... I've never taught the same course, because every time is entirely different, because it depends upon the people in the room, the context, the space we are in". Notwithstanding, it seems that the shift to online education led professors to be "suddenly focused on their teaching by accident" (Edmund), in an unprecedented way rethinking their practices and how to enact their responsibility in the unique context they found themselves and their students in. At the same time, however, and perhaps due to the pandemic context and the perceived lack of responsivity from students, professors often felt the need to provide students with more structure than they would in a face-to-face class:

I think with the online environment there is a little bit less flexibility because when students start, you want to give them a sense of security, that is well-planed, it's there, [so] they can find what they need without having to resort to me all the time. So everything needs to be there and needs to be laid out perfectly. So the degree of uncertainty about how certain things will unfold, I think needs to be less. Because if there's too much uncertainty, students get lost more easily in the online format. (Ian)

As it seems, the ethico-political aporia, or the im-possibility of responsibility (Fagan 2016), which is inevitably present in the face-to-face encounter, appears to have been emphasized in the online (and pandemic) context whereby teachers may find it difficult to think about individual students when everyone is lumped together in a faceless mass-an aspect that Sung and Mayer (2012) alluded to.

Derrida (2007) noted that an event is "an event insofar as what's happening was not predicted" (p. 456). He explained that an event also requires the possibility of repeatability for it to be an event, which seems to be highly pertinent to education. The frustrations professors faced did not only "accidently" lead them to rethink their practices-it illuminated the unpredictable, uncertain, and tenuous nature of teaching and relationality. Being forced to reassess one's teaching and the way they relate to students seems to have unveiled the complexities 
and ambiguities of an educator's responsibility in a more acute way than they might have perceived in normal circumstances.

Although a class has to be repeatable in nature (which is what allows teachers to prepare their classes), it is also "immediately engaged in substitution"; that is, "substitution is not simply the replacement of a replaceable uniqueness: substitution replaces the irreplaceable" (Derrida 2007, p. 452). Hospitable education goes beyond what one can plan; it requires preparedness for that which cannot be repeated, for "when I welcome a visitor, when I receive the visitation of an unexpected visitor, it must be a unique experience each and every time for it to be a unique, unpredictable, singular, and irreplaceable event" (Derrida 2007, p. 453). Hospitality requires "ignorance" (Todd 2003), undecidability, a constant suspension of decision, embracing the cipher without deciphering, however uncomfortable that might be. The tension between providing a structure to the course and being open to students' voices might have been heightened by professors' insecurities with the new format as well as trying to provide students with some certainties in the midst of an unprecedent context. It should be noted, however, that such undecidability is exactly what makes an ethic of hospitality possible and should not be perceived as a weakness-or perhaps be embraced exactly as the desirable weakness of education (Biesta 2009).

\section{Conclusion}

The present paper sought to analyze the challenges and complexities of hospitable education and the implications of such ethic to teachers' practices which were unveiled by the abrupt shift to online education caused by the COVID-19 pandemic. While professors did not necessarily approach teaching with hospitality intentions nor is it possible to claim that hospitality has taken place in their courses, analyzing teachers' experiences in light of the postulates of an ethic of hospitality brought forward some of the complex and nuanced facets of hospitable education, especially when students' physical absence is not an option. Although the promise of repetition is a necessary characteristic of education and of hospitality, the unique context created by the COVID-19 pandemic served to illustrate the unpredictable, unconditional and uncomfortable nature of hospitable education-challenges to be faced in every educational setting and context. Although physical presence or at least being able to see students' faces may facilitate bonding, hospitable education means welcoming the Other without knowing anything about the student, making no assumptions, and completely surrendering to the infinite alterity of the Other without expecting anything in return. When everything the teacher-host relies on is taken away, what is left is the responsibility they have for the one whom they do not even know the name, for the "voice without a look" (Derrida 2000, p. 31).

\section{Declarations}

Conflicts of interest I have no conflicts of interest to disclose.

\section{References}

Afrouz, R., and B. Crisp. 2021. Online education in social work, effectiveness, benefits, and challenges: A scoping review. Australian Social Work 74 (1): 55-67. https://doi.org/10.1080/0312407X.2020.18080 30 . 
Badia, A., C. Garcia, and J. Meneses. 2017. Approaches to teaching online: Exploring factors influencing teachers in a fully online university. British Journal of Educational Technology 48 (6): 1193-1207. https://doi.org/10.1111/bjet.12475.

Biesta, G., and D. Egéa-Kuehne, eds. 2001. Derrida \& education. New York, NY: Routledge.

Biesta, G. (2009). On the weakness of education. Philosophy of Education, 354-362.

Biocca, F., C. Harms, and J. Burgoon. 2003. toward a more robust theory and measure of social presence: Review and suggested criteria. Presence (Cambridge, Mass.) 12 (5): 456-480. https://doi.org/10.1162/ 105474603322761270.

Bryzzheva, L. 2018. "This Is a White Space”: On Restorative Possibilities of Hospitality in a Raced Space. Studies in Philosophy and Education 37 (3): 247-256.

Burke, K., and S. Larmar. 2020. Acknowledging another face in the virtual crowd: Reimagining the online experience in higher education through an online pedagogy of care. Journal of Further and Higher Education. https://doi.org/10.1080/0309877X.2020.1804536.

Comas-Quinn, A. 2011. Learning to teach online or learning to become an online teacher: An exploration of teachers' experiences in a blended learning course. ReCALL 23 (03): 218-232. https://doi.org/10.1017/ S0958344011000152.

Cook, J. 2018. Online Education and the Emotional Experience of the Teacher. New Directions for Teaching and Learning 2018 (153): 67-75. https://doi.org/10.1002/t1.20282.

Davis, C., R. Greenaway, M. Moore, and L. Cooper. 2019. Online teaching in social work education: Understanding the challenges. Australian Social Work 72 (1): 34-46. https://doi.org/10.1080/0312407X. 2018.1524918.

Derrida, J. 1978. Writing and difference. Routledge.

Derrida, J. 2000. Of hospitality. Stanford University Press.

Derrida, J. 2007. A certain impossible possibility of saying the event. Critical Inquiry 33 (2): 441-461.

Fagan, M. 2016. Ethics and politics after poststructuralism: Levinas. Derrida and Nancy: Edinburgh University Press.

Gonzalez, C. 2009. Conceptions of, and approaches to, teaching online: A study of lecturers teaching postgraduate distance courses. Higher Education 57 (3): 299-314. https://doi.org/10.1007/ s10734-008-9145-1.

Hagenauer, G., and S.E. Volet. 2014. Teacher-student relationship at university: An important yet underresearched field. Oxford Review of Education 40 (3): 370-388.

Hung, R. 2013. Educational hospitality and trust in teacher-student relationships: A Derridarian visiting. Studies in Philosophy and Education 32 (1): 87-99.

Jones, S. 2015. Benefits and challenges of online education for clinical social work: Three examples. Clinical Social Work Journal 43 (2): 225-235. https://doi.org/10.1007/s10615-014-0508-z.

Levinas, E. (1972). Humanisme de l'autre homme [Humanism of the Other]. Le Livre de Poche.

Levinas, E. (1982). Éthique et infini [Ethics and Infinity]. Le Livre de Poche.

Levinas, E. (1995). Altérité et transcendence [Alterity and Transcendence]. Le Livre de Poche.

Moreira, D. 2016. From on-campus to online: A trajectory of innovation, internationalization and inclusion. International Review of Research in Open and Distributed Learning: IRRODL 17 (5): 186-199.

Murphy, E., M. Rodríguez-Manzanares, and M. Barbour. 2011. Asynchronous and synchronous online teaching: Perspectives of Canadian high school distance education teachers. British Journal of Educational Technology 42 (4): 583-591. https://doi.org/10.1111/j.1467-8535.2010.01112.x.

Peters, M., and G. Biesta. 2009. Derrida, deconstruction, and the politics of pedagogy. New York, NY: Peter Lang.

Raza, S., Khan, K., \& Rafi, S. (2020). Online education \& MOOCs: Teacher self-disclosure in online education and a mediating role of social presence. The South Asian Journal of Management Sciences, 14(1), 142-158. https://doi.org/10.21621/sajms.2020141.08

Reamer, F. 2013. Distance and online social work education: Novel ethical challenges. Journal of Teaching in Social Work 33 (4-5): 369-384. https://doi.org/10.1080/08841233.2013.828669.

Ruitenberg, C. (2009). Giving place to unforeseeable learning: The inhospitality of outcomes-based education. Philosophy of education, 266-274.

Ruitenberg, C. 2011. The empty chair: Education in an ethic of hospitality. Philosophy of Education Archive 2011: $28-36$.

Ruitenberg, C. 2016. Unlocking the world: Education in an ethic of hospitality. New York, NY: Routledge.

Song, H., J. Kim, and N. Park. 2019. I know my professor: Teacher self-disclosure in online education and a mediating role of social presence. International Journal of Human-Computer Interaction 35 (6): 448 455. https://doi.org/10.1080/10447318.2018.1455126.

Sung, E., and R. Mayer. 2012. Five facets of social presence in online distance education. Computers in Human Behavior 28 (5): 1738-1747. https://doi.org/10.1016/j.chb.2012.04.014. 
Todd, S. (2003). Learning from the Other: Levinas, psychoanalysis, and ethical possibilities in education. State University of New York Press.

Tu, C., and M. McIsaac. 2002. The relationship of social presence and interaction in online classes. The American Journal of Distance Education 16 (3): 131-150. https://doi.org/10.1207/S15389286AJDE16 $03 \_2$.

Woods, R.H., and J.D. Baker. 2004. Interaction and immediacy in online learning. The International Review of Research in Open and Distributed Learning 5 (2): 1-13.

Yen, C., and C. Tu. 2011. A multiple-group confirmatory factor analysis of the scores for online social presence: Do they measure the same thing across cultural groups? Journal of Educational Computing Research 44 (2): 219-242. https://doi.org/10.2190/EC.44.2.e.

Zembylas, M. 2020. From the ethic of hospitality to affective hospitality: Ethical, political and pedagogical implications of theorizing hospitality through the lens of affect theory. Studies in Philosophy and Education 39 (1): 37-50.

Publisher's Note Springer Nature remains neutral with regard to jurisdictional claims in published maps and institutional affiliations. 